\title{
Verbal advice plus an information leaflet reduced antibiotic use in acute bronchitis
}

\section{Macfarlane J, Holmes W, Gard P, et al. Reducing antibiotic use for acute bronchitis in primary care: blinded, randomised
controlled trial of patient information leaflet. BMJ 2002 Jan 12;324:91-4. \\ Macfarlane J, Holmes W, Gard P, et al. Reducing antibiotic use for acute bronchitis in primary care: blinded, randomised
controlled trial of patient information leaflet. BMJ 2002 Jan 12;324:91-4. \\ QUESTION: In patients presenting with acute bronchitis, does verbal advice plus an information leaflet describing the uncertain value of antibiotics reduce antibiotic use more than verbal advice alone?}

\section{Design}

Randomised (unclear allocation concealment*), blinded (clinicians and data collectors),* controlled trial with 4 weeks of follow up.

\section{Setting}

3 general practices in Nottingham, UK.

\section{Patients}

259 patients $\geqslant 16$ years of age who had acute bronchitis (ie, illness for $\leqslant 21 \mathrm{~d}$; main symptom of cough; $\geqslant 1$ of sputum production, dyspnoea, wheeze, or chest discomfort or pain; and no alternative explanation) and were not receiving medical attention for an underlying disease, such as asthma, heart disease, or diabetes. 47 patients were judged to need antibiotics immediately. 212 patients were judged not to need antibiotics immediately and were subsequently randomly allocated (mean age 45 y, 58\% women). 205 of these patients $(97 \%)$ were included in the analysis.

\section{Intervention}

All patients received a prescription for antibiotics. 106 patients were allocated to verbal advice (read from a prompt card) by the general practitioner plus an information leaflet that described the natural course of lower respiratory tract symptoms and the advantages and disadvantages of antibiotic use. 106 patients were allocated to verbal advice alone.

\section{Main outcome measures}

Patient use of prescribed antibiotics (self report) within the next 2 weeks and initiation of further consultation for the same symptoms within the next 4 weeks.

\section{Main results}

Fewer patients who received verbal advice plus the information leaflet took their antibiotics than did patients who received verbal advice alone (table). The groups did not differ for reconsultation rates at 4 weeks $\{11 \%$ v $13 \%, \mathrm{p}=0.54\} \uparrow$.

\section{Conclusion}

Verbal advice plus an information leaflet describing the uncertain value of antibiotics reduced antibiotic use more than did verbal advice alone in patients with acute bronchitis.

*See glossary.

†Calculated from data in article.
Source of funding:

British Lung

Foundation..

For correspondence: Dr J Macfarlane, Nottingham City Hospital, Nottingham UK. john.macfarlane@ tinyworld.co.uk.

A modified version of this abstract also appears in

Evidence-Based

Nursing.

Physician verbal advice plus an information leaflet $v$ verbal advice alone for acute bronchitis

\begin{tabular}{cllll}
$\begin{array}{c}\text { Outcome at } \\
2 \text { weeks }\end{array}$ & $\begin{array}{l}\text { Verbal advice } \\
\text { plus leaflet }\end{array}$ & $\begin{array}{l}\text { Verbal advice } \\
\text { alone }\end{array}$ & RRR (95\% Cl) & NNT (Cl) \\
\hline Antibiotic use & $47 \%$ & $62 \%$ & $24 \%(3$ to 42$)$ & 7 (4 to 63$)$ \\
\hline
\end{tabular}

¥Abbreviations defined in glossary; RRR and $\mathrm{Cl}$ calculated from data in article.

\section{COMMENTARY}

Whether to prescribe an antibiotic for a lower respiratory tract infection is a common dilemma in primary care. The precise diagnosis is often unclear. ${ }^{1}$ Physicians are uncomfortable about prescribing antibiotics ${ }^{2}$ when the evidence suggests little benefit, ${ }^{3}$ but they have concerns about not prescribing them for patients who might benefit. They also wish to maintain good relationships ${ }^{4}$ with patients who almost always expect an antibiotic. ${ }^{5}$

The "delayed prescription" along with a discussion of the pros and cons of antibiotics provide a useful escape from this dilemma: this technique avoids a power struggle and invites patients to participate in the decision. For patients with pharyngitis or otitis, delayed prescribing has not only decreased antibiotic use but has also changed patient perceptions about respiratory infections and decreased subsequent visits for uncomplicated respiratory illnesses. ${ }^{6}$

Although the "delayed prescription" approach is appealing, it is clearly not the final answer. Half of the patients in the trial by Macfarlane $e t$ al took the antibiotics that their physicians felt were unnecessary. Nevertheless, many patients respond well to the information that no antibiotic is required and are happy to leave the physician's office without a prescription. For patients who still feel they need an antibiotic, a delayed prescription is a reasonable choice and should be accompanied by written materials.

Lorne A Becker, MD

SUNY Upstate Medical University

Syracuse, New York, USA

1 Hueston WJ, Mainous AG 3rd, Dacus EN, et al. Does acute bronchitis really exist? A reconceptualization of acute viral respiratory infections. J Fam Pract 2000;49:401-6.

2 Butler CC, Rollnick S, Pill R, et al. Understanding the culture of prescribing: qualitative study of general practitioners' and patients' perceptions of antibiotics for sore throats. BMJ 1998;317:637-42.

3 Smucny J, Fahey T, Becker L, et al. Antibiotics for acute bronchitis. Cochrane Database Syst Rev 2002(1):CD000245.

4 Coenen S, Van Royen P, Vermeire E, et al. Antibiotics for coughing in general practice: a qualitative decision analysis. Fam Pract 2000;17:380-5.

5 Macfarlane J, Holmes W, Macfarlane R, et al. Influence of patients' expectations on antibiotic management of acute lower respiratory tract illness in general practice: questionnaire study. BMJ 1997;315:1211-4.

6 Little P, Gould C, Williamson I, et al. Reattendance and complications in a randomised trial of prescribing strategies for sore throat: the medicalising effect of prescribing antibiotics. BMJ 1997;315:350-2. 